\title{
Effects of Toll-like Receptors 3 and 4 Induced by Titanium Dioxide Nanoparticles in DNA Damage-Detecting Sensor Cells
}

Karim Samy El-Said ${ }^{1,2}$, Ehab Mostafa Ali², Koki Kanehira ${ }^{3}$ and Akiyoshi Taniguchi* ${ }^{\text {* }}$

${ }^{1}$ Cell-Material Interaction Group, Biomaterial Unit, Nano-Bio Field, Interaction Center for Material Nanoarchitectonics (MANA), National Institute for Materials Science (NIMS), Japan

${ }^{2}$ Department of Chemistry, Faculty of Science, Tanta University, Egypt

${ }^{3}$ Biotechnology Group, TOTO Ltd. Research Institute, Honson 2-8-1, Chigasaki, Kanagawa 253-8577, Japan

\begin{abstract}
Live cell-based sensor reporter systems (so-called sensor cells) were employed to detect host defense systems, including DNA damage response, stimulated by nanoparticles (NPs). Our previous work established the use of DNA damage-detecting sensor cells containing the B-cell translocation gene 2(BTG2) promoter-reporter plasmid and showed that Toll-like receptors (TLRs) are involved in the cellular response and uptake of $\mathrm{TiO}_{2} \mathrm{NPs}$. These results suggested that TLRs could be involved in many cellular responses. However, the effect of TLRs on DNA damage induced by $\mathrm{TiO}_{2} \mathrm{NPs}$ is unknown. Here we investigated the role of TLR 3 and 4 in DNA damage induced by PEGmodified $\mathrm{TiO}_{2}$ and by $\mathrm{TiO}_{2} \mathrm{NPs}$. The results show that PEG modification of $\mathrm{TiO}_{2} \mathrm{NPs}$ reduces DNA damage response compared to unmodified $\mathrm{TiO}_{2}$ NPs. The overexpression of TLR3 reduces DNA damage mediated by both $\mathrm{TiO}_{2}$ and PEG-TiO ${ }_{2}$ NPs. In contrast, overexpression of TLR4 increases the DNA damage response induced by $\mathrm{TiO}_{2} \mathrm{NPs}^{2}$ The results indicate that co-transfection of TRL4 expression vector affects the sensitivity of DNA damage response, but does not affect the detection limit of the DNA damage response. These finding will aid in understanding the molecular interaction mechanisms between NPs and cells.
\end{abstract}

Keywords: Titanium dioxide nanoparticles; PEG-TiO 2 modification; Live cell-based biosensors; DNA damage response; Toll-like receptors

\section{Introduction}

Nanoparticles (NPs) are tiny particles (diameter of 1 to $100 \mathrm{~nm}$ in at least one dimension) [1] characterized by a very high surface area-to-volume ratio [2]. Due to the unique properties afforded by their size, NPs possess a wide range of applications in the industrial, electrical, agricultural, pharmaceutical, and medical fields. Titanium dioxide $\left(\mathrm{TiO}_{2}\right)$ NPs are used as a photocatalyst [3] for cleaning air and water, and are found in a wide array of products including paints, pigments, cosmetics, and skin care products [4]. $\mathrm{TiO}_{2} \mathrm{NPs}_{\text {are classified }}$ as a biologically inert substance in animals and humans $[5,6]$. Recent findings have revealed that rats exposed to ultra-fine $\mathrm{TiO}_{2} \mathrm{NPs}$ develop inflammation, pulmonary damage, and lung tumors $[7,8]$. This toxicity may be due to the ease with which these NPs can pass through the cell membrane and disrupt biological systems [9]. It has been suggested that the small size and corresponding high specific surface area are the major determinants of NP toxicity [10]. It has also been proposed that the high surface area of NPs greatly increases their ability to produce potentially toxic Reactive Oxygen Species (ROS) [11].

Live cell-based sensor reporter systems (so-called sensor cells) have been employed to study host defense systems, including innate immune response, environmental stress response and DNA damage response, stimulated by NPs. The attraction of systems employing sensor cells is that they are highly sensitive and effective compared with traditional methods [12]. Our previous work established three kinds of live cell-based sensor reporter systems: a nuclear factor kappa B (NF-кB) reporter system [13], a Heat Shock Protein (HSP) reporter system $[14,15]$ and a B-cell translocation gene 2 (BTG2) system [16]. These results suggested that these three sensor cells hold promise for detecting cellular response to NPs.

Polyethylene Glycol (PEG) is a coiled polymer of repeating ethylene ether units with a dynamic conformation. PEG is inexpensive, versatile and FDA-approved for many applications [17]. In addition,
PEG is non-toxic and non-immunogenic, and has favorable pharmacokinetics and tissue distribution [18]. Modifying the surface of NPs with PEG (PEGylation) not only prevents agglomeration [19], but also renders NPs resistant to protein adsorption and enhances their biocompatibility [20]. Coating nanomaterials with PEG also increases the in vivo circulation time, thereby likely reducing clearance via the ReticuloEndothelial System (RES) [21]. We have already shown that PEGylation of $\mathrm{TiO}_{2} \mathrm{NPs}$ reduces cytotoxity and inflammatory response [22]. The results suggested that $\mathrm{PEGylation}$ of $\mathrm{TiO}_{2} \mathrm{NPs}$ could reduce many cellular responses. However, the effect of PEGylation of $\mathrm{TiO}_{2} \mathrm{NPs}$ on cellular DNA damage is unknown.

DNA damages are abnormal chemical and structural alterations, mutations ordinarily involve the normal four bases in new arrangements. Cellular DNA damage is caused by chemicals or ionizing radiation and can lead to proliferation and cancer. The most important guardian of the genome is p53, a tumor suppressor protein. p53 triggers cellular outcomes through its role as a sequence-specific DNA-binding transcriptional factor of genes involved in regulation of the cell cycle, apoptosis, and DNA repair in response to DNA damage [23,24]. B-cell translocation gene 2 (BTG2) is involved in cell-growth control, and BTG2 expression is regulated by p53 [25]. BTG2 expression is

${ }^{*}$ Corresponding author: Prof. Dr. Akiyoshi Taniguchi, Director of Cell-Materia Interaction Group, National Institute for Materials Science (NIMS) 1-1 Namiki, Tsukuba, Ibaraki 305-0044, Japan, Tel: +81-29-860-4505; E-mail: taniguchi.akiyoshi@nims.go.jp

Received September 25, 2013; Accepted November 07, 2013; Published November 14, 2013

Citation: El-Said KS, Ali EM, Kanehira K, Taniguchi A (2013) Effects of Toll-like Receptors 3 and 4 Induced by Titanium Dioxide Nanoparticles in DNA DamageDetecting Sensor Cells. J Biosens Bioelectron 4: 144. doi: 10.4172/21556210.1000144

Copyright: (c) 2013 El-Said KS, et al. This is an open-access article distributed under the terms of the Creative Commons Attribution License, which permits unrestricted use, distribution, and reproduction in any medium, provided the original author and source are credited. 
upregulated by p53 after DNA damage induced by a genotoxic agent [26]. We have established sensor cells for DNA damage detection using BGT2 promoter-reporter plasmid (DNA damage-detecting sensor cells) [27], and have shown that this type of sensor cell can detect DNA damage induced by $\mathrm{TiO}_{2}$ NPs [16].

Toll-like receptors (TLRs) play an essential role in the activation of innate immunity by recognizing specific molecular patterns of microbial components. TLRs are transmembrane proteins that comprise both an extra-cellular domain (responsible for ligand recognition) and a cytoplasmic domain (required for initiating signaling) [28]. As suggested by their range of ligands and subcellular locations, TLRs recognize a wide range of 'foreign' materials $[29,30]$. We have previously shown that TLRs are also involved in the cellular response and cellular uptake of $\mathrm{TiO}_{2}$ NPs [31,32]. These results suggested that TLRs could be involved in many cellular responses. However, the effect of TLRs on DNA damage induced by $\mathrm{TiO}_{2}$ NPs is unknown.

In this investigation we studied the role of TLR3 and TLR4 in cellular DNA damage response induced by exposure to $\mathrm{TiO}_{2}$ and PEGmodified $\mathrm{TiO}_{2}$ NPs (PEG-TiO 2 NPs). The aim of this work was to improve the sensitivity and detection limit of DNA damage-detecting sensor cells following transfection with TLR3 and TLR4 expression vectors. The results indicate that co-transfection with TRL4 expression vector affects the sensitivity of DNA damage-detecting sensor cells, but does not affect the detection limit of the DNA damage response. This information is important for the detection of nano-toxicological response.

\section{Materials and Methods}

\section{Cells and cell culture}

The human hepatocellular carcinoma cell line, HepG2, was cultured in Dulbecco's Modified Eagle's Medium (DMEM, Nacalai Tesque, Inc., Kyoto, Japan) supplemented with $10 \%$ fetal bovine serum (FBS, Biowest, Nuaillé, France, UK), $100 \mathrm{U} / \mathrm{mL}$ penicillin, and 100 $\mu \mathrm{g} / \mathrm{mL}$ streptomycin (Nacalai Tesque, Inc.,) at $37^{\circ} \mathrm{C}$ in a humidified atmosphere containing $5 \% \mathrm{CO}_{2}$.

\section{Plasmids employed}

pGL3-Control vector (pGL3 plasmid; Promega, Madison, WI, USA) was employed as an 'empty' control reporter plasmid. BTG2 promoter-reporter plasmid (the region from nt -100 to $-20 \mathrm{bp}$ of the BTG2 gene containing the p53 binding site mutation [27]), and TLR3 and TLR4 promoter-reporter plasmids, were used to detect the DNA damage response. All the reporter plasmids contain SV40 promoters and enhancer sequences, resulting in strong expression of the luciferaseencoding gene (luc ${ }^{+}$) in many types of mammalian cells. The pRL-CMV vector (CMV, Renilla luciferase-encoding control plasmid; Promega) contains the CMV promoter upstream of the Renilla luciferase gene and was used as an internal control for variations in transfection efficiency. TLR-encoding genes were purchased from InvivoGen (San Diego, CA, USA). The pUNO1-mcs expression vector was used as an 'empty' control vector. Since pUNO1-mcs does not contain a therapeutic gene, it can be used in conjunction with other vectors of the pUNO1 family to serve as an experimental control. Overproduction of TLR3 and TLR4 was provided by transfection with pUNO-hTLR3 (which encodes the human TLR3 protein), and pUNO1-hTLR04a (CD284a) (which harbors the human TLR04a (CD284a) encoding open reading frame), respectively.

\section{Construction of DNA damage-detecting sensor cells}

Reporter plasmid (blank control reporter, pGL3 plasmid or BTG2 promoter-reporter plasmid) and internal control plasmid (pRL-CMV vector) were co-transfected into HepG2 cells. The transfection was performed with Lipofectamine ${ }^{\mathrm{TM}}$ LTX Reagent (Invitrogen, Carlsbad, CA, USA) according to the supplier's protocol. HepG2 cells were seeded in 24-well plates. After overnight incubation, the cells were cotransfected with the plasmids using Lipofectamine ${ }^{\mathrm{TM}}$ LTX Reagent. For co-transfection experiments, reporter plasmid (blank control reporter, pGL3 plasmid or BTG2 promoter-reporter plasmid), TLR3 or TLR4 expression vectors and internal control plasmid (pRL-CMV vector) were co-transfected into HepG2 cells.

\section{Preparation of and exposure to $\mathrm{TiO}_{2} \mathrm{NP}$}

The preparation and characterization of $\mathrm{TiO}_{2} \mathrm{NPs}$ were described in previous studies $[13,14]$. Briefly, nano- $\mathrm{TiO}_{2}$ (AeroxideR P25; Sigma-Aldrich, St Louis, MO, USA) was dispersed in distilled water and autoclaved at $120^{\circ} \mathrm{C}$ for $20 \mathrm{~min}$. The suspension was cooled to room temperature and then sonicated for $10 \mathrm{~min}$ at $200 \mathrm{kHz}$ using a high-frequency ultrasonic sonicator (MidSonic 600, Kaijo Corp., Tokyo, Japan). The resulting nano- $\mathrm{TiO}_{2}$ suspension was designated ' $\mathrm{TiO}_{2}$ NPs'. The concentration of $\mathrm{TiO}_{2}$ NPs was determined using a UV-vis spectrophotometer (UV-1600, Shimadzu, Kyoto, Japan). The suspension was adjusted to the desired concentration by the addition of distilled water and stored at $4^{\circ} \mathrm{C}$ until use. The particle size distribution was measured by dynamic light scattering (Zetasizer Nano-ZS, Malvern Instruments, Malvern, UK). The aggregated particle size of the $\mathrm{TiO}_{2}$ NPs was determined to be $216 \pm 70 \mathrm{~nm}$. The size of the aggregated $\mathrm{TiO}_{2}$ NPs remained stable for several weeks under the indicated storage conditions. Prior to addition to the cell cultures, the suspension of $\mathrm{TiO}_{2} \mathrm{NPs}$ was diluted into supplemented medium and used as described above. For the reporter gene (transfected cell) assays, the culture medium was replaced (1 day after transfection) with medium containing the $\mathrm{TiO}_{2}$ NPs at the intended concentration. Specifically, $\mathrm{TiO}_{2} \mathrm{NPs}$ were added to the culture medium immediately before the medium was applied to the cells. After the indicated exposure times, the cells were harvested and assayed for luciferase activity. Polyethylene glycol nanoparticles $\left(\mathrm{PEG}-\mathrm{TiO}_{2}\right)$ were prepared as described previously [33].

\section{Luciferase activity assessment}

The luciferase activities were assessed by the Dual-Luciferase Reporter Assay System (Promega, Madison, WI, USA), as described previously $[13,14]$. Following $\mathrm{TiO}_{2} \mathrm{NP}$ exposure, the cells were lysed in $1 \times$ passive lysis buffer, then luciferase and Renilla light units were measured using a Lumat LB9507 (Berthold Technologies, Bad Wildbad, Germany) luminometer according to the manufacturer's protocol for the Dual Luciferase assay. All the results represent at least three independent tests. Data are expressed as means \pm Standard Deviations (S.D.).

\section{Results and Discussion}

We have previously shown that uncoated $\mathrm{TiO}_{2} \mathrm{NP}$ aggregates induce DNA damage response [16]. Botelho et al. also have shown that $\mathrm{TiO}_{2}$ NPs induce DNA damage response and participate in a number of carcinogenesis-mediated processes, such as increased cell proliferation, decreased apoptosis and increased oxidative stress in human gastric epithelial cells in vitro [34]. In order to reduce the DNA damage response, we conjugated $\mathrm{TiO}_{2} \mathrm{NPs}$ with polyethylene glycol (PEG). In this study, a live cell-based biosensor based on a B-cell Translocation 
Gene 2 (BTG2) promoter-reporter was used to detect DNA damage response induced by $\mathrm{PEG}-\mathrm{TiO}_{2} \mathrm{NPs}$ and $\mathrm{TiO}_{2} \mathrm{NPs}$ in $\mathrm{BTG} 2$ promoterreporter plasmid transfected HepG2 cells. In previous work, a BTG2 biosensor for the BTG2 promoter response detected the cytotoxicity caused by DNA strand breaks with high sensitivity [27]. As shown in

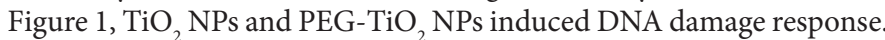
HepG2 cells exposed to PEG-TiO ${ }_{2}$ NPs showed a 2.2 times higher DNA damage response compared to the control, while cells exposed to $\mathrm{TiO}_{2}$ NPs showed a 4.9 times higher DNA damage response compared with the control. The results indicate that PEG modification reduces DNA damage response induced by $\mathrm{TiO}_{2} \mathrm{NPs}$.

Toll-like receptors (TLRs) recognize and respond to exogenous and endogenous ligands through signaling pathways, leading to inflammatory cascade mediator production which directs the innate and adaptive immune response. TLRs are conserved membrane-bound Pattern Recognition Receptors (PRRs) that recognize a broad spectrum of microbial components such as lipopeptides and non-self nucleic acids [35]. We have previously shown that TLRs are involved in $\mathrm{TiO}_{2}$ NP cellular uptake $[31,32]$. In order to investigate the effect of TLRs on DNA damage response induced by NPs, live cell-based sensor cells incorporating the BTG2 promoter-reporter, and either the TLR 3 or TLR4 expression vector, were used to detect the DNA damage response induced by PEG-TiO 2 NPs and $\mathrm{TiO}_{2}$ NPs. The concentration of both NPs was standardized at $10 \mu \mathrm{g} / \mathrm{ml}$ and the exposure times ranged from $3 \mathrm{~h}$ to $48 \mathrm{~h}$. As shown in Figure 2, HepG2 cells transfected with TLR3 and exposed to $\mathrm{TiO}_{2}$ NPs showed decreased BTG2 response compared to cells without TLR transfection. In contrast, HepG2 cells transfected with TLR4 showed a higher BTG2 response, as measured by the BTG2 promoter-luciferase reporter plasmid, compared to HepG2 cells without TLR transfection. The highest BTG2 response of cells transfected with TLR4 compared to cells without TLR transfection was at $48 \mathrm{~h}$ exposure to the $\mathrm{TiO}_{2}$ NPs. The response of cells transfected with TLR4 was 5.5 times that of cells transfected with TLR3, and that of the control cells was 3.9 times that of cells transfected with TLR3 (Figure 2). The results indicate that TLR4 enhanced DNA damage induced by $\mathrm{TiO}_{2} \mathrm{NPs}$ and that TLR3 reduced DNA damage induced by $\mathrm{TiO}_{2} \mathrm{NPs}$.

On the other hand, HepG2 cells transfected with TLR4 and exposed to PEG-TiO 2 NPs showed no effect (Figure 3), while cells transfected

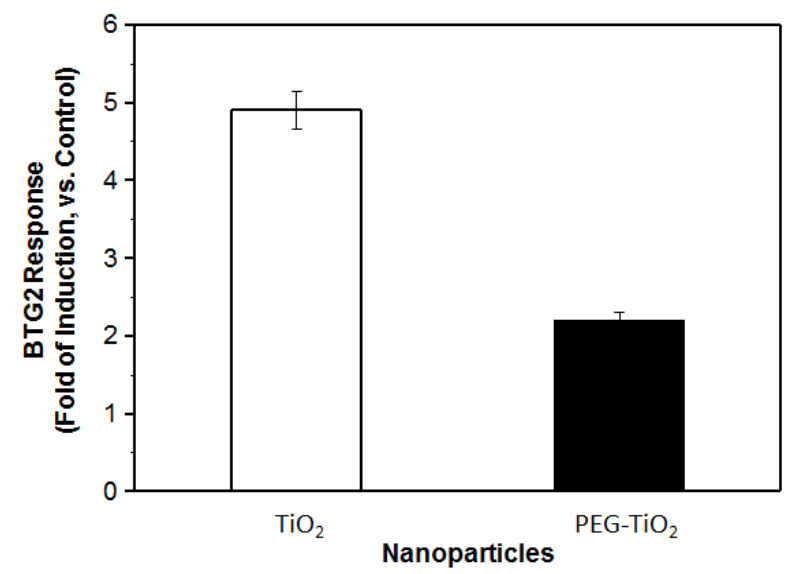

Figure 1: Comparison of BTG2 response induced by $\mathrm{TiO}_{2}$ and $\mathrm{PEG}-\mathrm{TiO}_{2} \mathrm{NPs}$ compared to the control (cells not exposed to NPs). Cells were exposed to 10 $\mu \mathrm{g} / \mathrm{mL}$ of either $\mathrm{TiO}_{2}$ or PEG-TiO ${ }_{2} \mathrm{NPs}$ for $48 \mathrm{~h}$. Each column was produced from at least 3 replicate measurements. All values are presented as mean \pm S.D. $(n \geq 3)$.

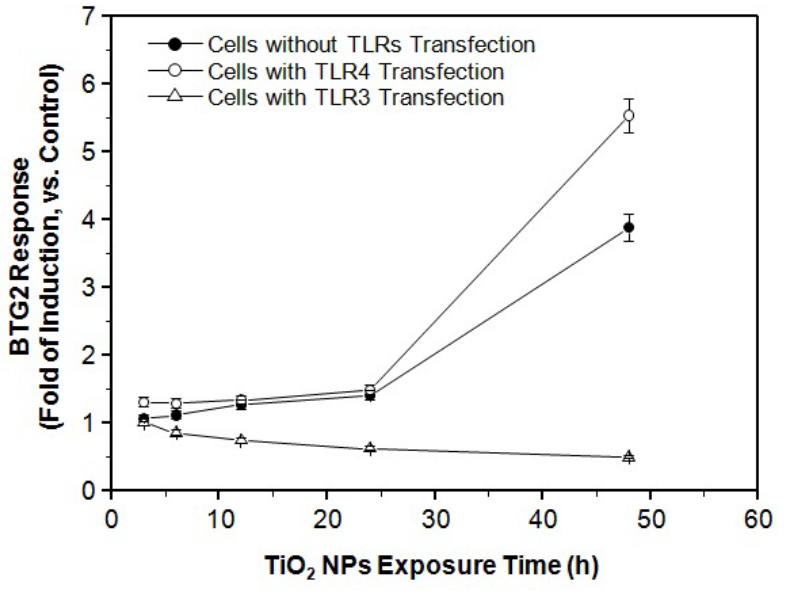

Figure 2: Time course of HepG2 exposure to $\mathrm{TiO}_{2} \mathrm{NPs}$. The cells were transfected with BTG2 promoter-reporter plasmid and co-transfected with or without TLR3 and TLR4 expression vectors. The transfected cells were exposed to $10 \mu \mathrm{g} / \mathrm{mL} \mathrm{TiO}{ }_{2}$ NPs for the indicated lengths of time. Each plot was produced from at least 3 replicate measurements. All values are presented as mean \pm S.D. $(n \geq 3)$.

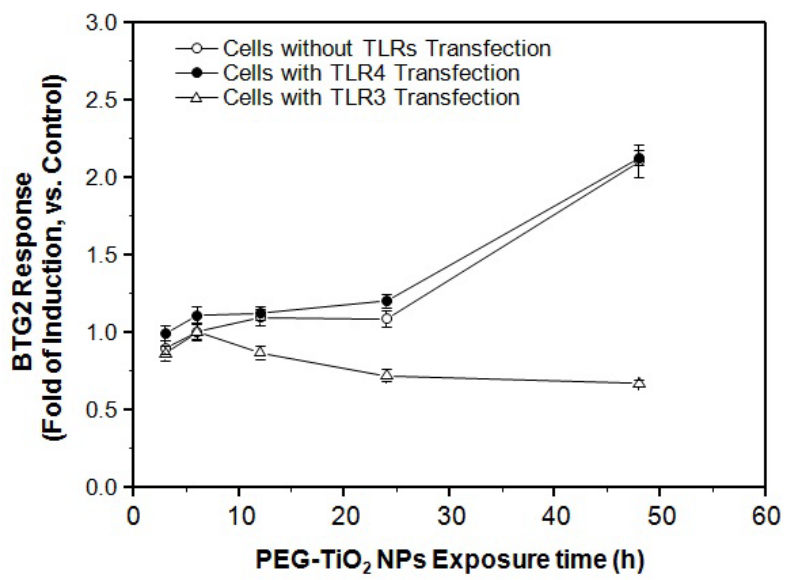

Figure 3: Time course of HepG2 exposure to PEG-TiO NPs. The cells were transfected with BTG2 promoter-reporter plasmid and co-transfected with or without TLR3 and TLR4 expression vectors. The transfected cells were exposed to $10 \mu \mathrm{g} / \mathrm{mL} \mathrm{TiO}{ }_{2}$ NPs for the indicated lengths of time. Each plot was produced from at least 3 replicate measurements. All values are presented as mean \pm S.D. $(n \geq 3)$.

with TLR3 showed a decrease in BTG2 response compared with nontransfected cells. The highest BTG2 response (2.1 times compared to the control) occurred after $48 \mathrm{~h}$ exposure to $\mathrm{PEG}-\mathrm{TiO}_{2} \mathrm{NPs}$. The results indicate that TLR4 did not enhance DNA damage induced by PEG$\mathrm{TiO}_{2} \mathrm{NPs}$, and that TLR3 reduced DNA damage induced by PEG-TiO NPs.

In order to compare the effect of TLR4 on the sensitivity and detection limit of DNA damage response, the dependence of the DNA damage response on $\mathrm{TiO}_{2} \mathrm{NP}$ concentration was investigated. It is clear from Figure $4 \mathrm{a}$ that an increase in the concentration of $\mathrm{TiO}_{2} \mathrm{NPs}$ increased the BTG2 response of HepG2 cells transfected with BTG2 promoter-luciferase reporter plasmid with or without transfection with the TLR4 expression vector. The highest BTG2 response was at $10 \mu \mathrm{g} /$ 

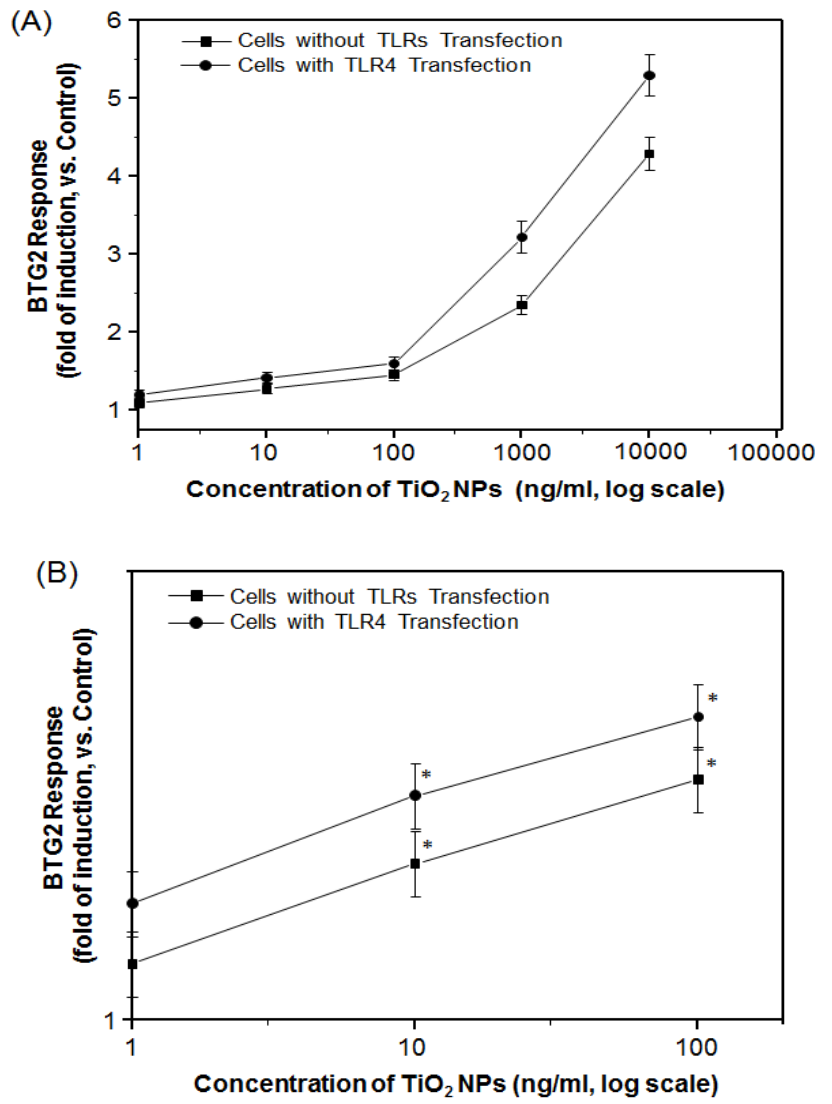

Figure 4: (a) Effect of TLR4 on BTG2 response (fold of induction) of HepG2 cells transfected with BTG2 promoter-luciferase reporter plasmid and TLR4 expression vector. (b) An expanded view of the response at low concentrations of $\mathrm{TiO}_{2}$ NPs. Transfected cells were exposed to the indicated concentrations of $\mathrm{TiO}_{2} \mathrm{NPs}$ for $48 \mathrm{~h}$. The results are shown as mean \pm S.D., $\mathrm{n} \geq 3$ for each concentration.

$\mathrm{ml}$, and cells transfected with TLR4 showed a higher BTG2 response (5.2 times higher compared to cells not transfected with TLRs). This result indicated that co-transfection with TLR4 expression vector increases sensitivity towards DNA damage response. Figure $4 \mathrm{~b}$ shows an expanded view of the BTG response of HepG2 cells exposed to low concentrations $\mathrm{TiO}_{2} \mathrm{NPs}$. The detection limit of DNA damage response by HepG2 cells transfected with BTG2 promoter-reporter plasmid with or without TLR4 expression vector was $10 \mathrm{ng} / \mathrm{ml}$ of $\mathrm{TiO}_{2} \mathrm{NPs}$. The results indicate that co-transfection with TRL4 expression vector does not affect the detection limit of the DNA damage response.

In the present study, we focused on the roles of TLR3 and TLR4 in the DNA damage response induced by $\mathrm{PEG}-\mathrm{TiO}_{2}$ and $\mathrm{TiO}_{2} \mathrm{NPs}$. TLRs have been studied for their role in the recognition of microbial pathogens. Each TLR recognizes a specific pathogen-associated pattern. For example, TLR 3 localizes to the endosome surface and recognizes viral double-stranded RNA [36], whereas TLR 4 localizes to the cell surface and binds with Gram-negative bacterial cell wall components such as LPS [37]. Transfection of HepG2 cells with TLRs could change the DNA damage response induced by $\mathrm{TiO}_{2}$ and PEG-TiO ${ }_{2} \mathrm{NPs}$. We hypothesize that transfection with TLR4 expression vector elevates the level of TLR4 on the cell surface, thus increasing the uptake of $\mathrm{TiO}_{2}$ NPs in the cytoplasm and hence increasing the risk of DNA damage response. On the other hand, elevated levels of subcellular TLR3 could combine with unengaged $\mathrm{TiO}_{2}$ and PEG-TiO $\mathrm{NPs}_{2}$ in the cytoplasm and retain those NPs in the endosome, thereby reducing the risk of cytotoxicity and DNA damage mediated by both $\mathrm{TiO}_{2}$ and PEG-TiO NPs. Hence, the cellular locations of TLR3 and TLR4 could result in opposing effects on DNA damage response induced by $\mathrm{TiO}_{2} \mathrm{NPs}$.

\section{Conclusions}

Our results show that PEG modification of $\mathrm{TiO}_{2}$ causes reduced DNA damage response compared with $\mathrm{TiO}_{2} \mathrm{NPs}$. The overexpression of TLR3 reduced DNA damage mediated by both $\mathrm{TiO}_{2}$ and $\mathrm{PEG}-\mathrm{TiO}_{2}$ NPs. In contrast, overexpression of TLR4 increased the DNA damage response induced by $\mathrm{TiO}_{2} \mathrm{NPs}$. Our results indicate that co-transfection of TRL4 expression vector affects the sensitivity of the DNA damage response, but does not affect the detection limit of the DNA damage response.

\section{References}

1. Ng CT, Li JJ, Perumalsamy R, Watt F, Yung LYL, et al. (2010) Localizing cellular uptake of nanomaterials in vitro by transmission electron microscopy. Microsc Sci Technol Appl Educ 1: 316-320.

2. Ratyakshi, Chauhan RP (2009) Colloidal synthesis of silver nanoparticles. Asian J Chem 21: S113-S116.

3. Fujishima A, Rao TN, Tryk DA (2000) Titanium dioxide photocatalysis. J Photochem Photobiol C 1: 1-21.

4. Chen X, Mao SS (2007) Titanium Dioxide Nanomaterials: Synthesis, Properties, Modifications, and Applications. Chem Rev 107: 2891-2959.

5. Chen E, Ruvalcaba M, Araujo L, Chapman R, Chin WC (2008) Ultrafine titanium dioxide nanoparticles induce cell death in human bronchial epithelial cells. J Exp Nanosci 3: 171-183.

6. Gurr JR, Wang ASS, Chen CH, Jan KY (2005) Ultrafine titanium dioxide particles in the absence of photoactivation can induce oxidative damage to human bronchial epithelial cells. Toxicology 213: 66-73.

7. Oberdorster G, Ferin J, Gelein R, Soderholm SC, Finkelstein J (1992) Role of the alveolar macrophage in lung injury: studies with ultrafine particles. Environ Health Perspect 97: 193-199.

8. Baggs RB, Fern J, Oberdorster G (1997) Regression of pulmonary lesions produced by inhaled titanium dioxide in rats. Vet Pathol 34: 592-597.

9. Mishra VK, Mishra SK, Jha A (2008) Application of nanomaterials in mesenchymal stem cell engineering. Dig J Nanomater Biostructures 3: 203-208.

10. Huang CC, Aronstam RS, Chen DR, Huang YW (2010) Oxidative stress, calcium homeostasis, and altered gene expression in human lung epithelial cells exposed to ZnO nanoparticles. Toxicol. In Vitro 24: 45-55.

11. Pujalte I, Passagne I, Brouillaud B, Treguer M, Durand E, et al. (2011) Cytotoxicity and oxidative stress induced by different metallic nanoparticles on human kidney cells. Part Fibre Toxicol 8 doi:10.1186/1743-8977-8-10.

12. Taniguchi A (2010) Live cell-based sensor cells. Biomaterials 31: 5911-5915

13. Chen P, Migita S, Kanehira K, Sonezaki S, Taniguchi A (2011) Development of sensor cells using NF-kB pathway activation for detection of nanoparticlesinduced inflammation. Sensors 11: 7219-7230.

14. Chen P, Kanehira K, Sonezaki S, Taniguchi A (2012) Detection of cellular response to titanium dioxide nanoparticle agglomerates by sensor cells using heat shock protein promoter. Biotechnol Bioeng 109: 3112-3118.

15. Wada K, Taniguchi A, Okano T (2007) Highly sensitive detection of cytotoxicity using a modified HSP70B' promoter. Biotechnol Bioeng 97: 871-876.

16. Chen P, Taniguchi A (2012) Detection of DNA damage response caused by different forms of titanium dioxide nanoparticles using sensor cells. J Biosens Bioelectron 3: 129. doi:10.4172/2155-6210.1000129.

17. Jokerst JV, Lobovkin T, Zare RN, Gambhir SS (2011) Nanoparticle PEGylation for imaging and therapy. Nanomedicine 6: 715-728.

18. Wang W, Xiong W, Wan J, Sun X, Xu H, et al. (2009) The decrease of PAMAM dendrimer-induced cytotoxicity by PEGylation via attenuation of oxidative stress. Nanotechnology 20: 105103-105109. 
Citation: El-Said KS, Ali EM, Kanehira K, Taniguchi A (2013) Effects of Toll-like Receptors 3 and 4 Induced by Titanium Dioxide Nanoparticles in DNA Damage-Detecting Sensor Cells. J Biosens Bioelectron 4: 144. doi: 10.4172/2155-6210.1000144

Page 5 of 5

19. Matsumura S, Sato S, Yadasaka M, Tomida A, Tsuruo T, et al. (2009) Prevention of carbon nanohorn agglomeration using a conjugate composed of comb-shaped polyethylene glycol and a peptide aptamer. Mol Pharmaceutics 6: 441-447.

20. Eck W, Craig G, Sigdel A, Ritter G, Old LJ, et al. (2008) PEGylated gold nanoparticles conjugated to monoclonal F19 antibodies as targeted labeling agents for human pancreatic carcinoma tissue. ACS Nano 2: 2263-2272.

21. Prencipe G, Tabakman SM, Welsher K, Liu Z, Goodwin AP, et al. (2009) PEG branched polymer for functionalization of nanomaterials with ultralong blood circulation. J Am Chem Soc 131: 4783-4787.

22. Mano SS., Kanihira K, Sonezaki S, Taniguchi A (2012) Effect of Polyethylene Glycol Modification of $\mathrm{TiO}_{2}$ Nanoparticles on Cytotoxicity and Gene Expressions in Human Cell Lines. Int J Mol Sci 13: 3703- 3717.

23. Hollstein M, Sidransky D, Vogelstein B, Harris CC (1991) p53 mutations in human cancers. Science 253: 49-53.

24. Lane DP (1992) Cancer p53, guardian of the genome. Nature 358: 15-16.

25. Rouault JP, Rimokh R, Tessa C, Paranhos G, Ffrench M, et al. (1992) BTG1, a member of a new family of antiproliferative genes. EMBO J 11: 1663-1670.

26. Rouault JP, Falette N, Guéhenneux F, Guillot C, Rimokh R, et al. (1996) Identification of BTG2, an antiproliferative p53-dependent component of the DNA damage cellular response pathway. Nat Genet 14: 482-486.

27. Wada K, Hamaguchi Y, Furukawa K, Taniguchi A (2009) DNA damage sensible engineered promoter for cellular biosensing of cytotoxicity. Biotechnol Bioeng 102: 1460-1465.

28. Huyton T, Rossjohn J, Wilce M (2007) Toll-like receptors: structural pieces of a curve-shaped puzzle. Immunol Cell Biol 85: 406-410.
29. Trinchieri G, Sher A (2007) Cooperation of Toll-like receptors signals in innate immune defense. Nat Rev Immunol 7: 179-190.

30. Kawai T, Akira S (2010) The role of pattern-recognition receptors in innate immunity: update on Toll-like receptors. Nat Immunol 11: 373-384.

31. Mano SS, Kanehira K, Sonezaki S, Taniguchi A (2013) Toll-like receptor 4 is involved in titanium dioxide nanoparticle incorporation into cells. Sci Adv Mater in press.

32. Chen P, Migita S, Kanehira K, Taniguchi A (2013) Role of toll-like receptors 3 , 4 and 7 in cellular uptake and response to titanium dioxide nanoparticles. Sci Tech Adv Mater 14, doi:10.1088/1468-6996/14/1/015008.

33. Yamaguchi S, Kobayashi H, Narita T, Kanehira K, Sonezaki S, et al. (2011) Sonodynamic therapy using water-dispersed $\mathrm{TiO}_{2}$-polyethylene glycol compound on glioma cells: Comparison of cytotoxic mechanism with photodynamic therapy. Ultrason Sonochem 18: 1197-1204.

34. Botelho MC, Costa C, Silva S, Costa S, Dhawan A, et al. (2013) Effects of titanium dioxide nanoparticles in human gastric epithelial cells in vitro. Biomed Pharmacother in press.

35. Akira S, Uematsu S, Takeuchi O (2006) Pathogen recognition and innate immunity. Cell 124: 783-801.

36. Alexopoulou L, Holt AC, Medzhitov R, Flavell RA (2001) Recognition of doublestranded RNA and activation of NF-KB by Toll-like receptor 3. Nature 413: 732738.

37. Takeuchi O, Hoshino K, Kawai T, Sanjo H, Takada H, et al. (1999) Differential roles of TLR2 and TLR4 in recognition of gram-negative and gram-positive bacterial cell wall components. Immunity 11: 443-445. 